\title{
Key problems analysis of large-diameter pipeline tapping machine's design and manufacture
}

\author{
LI Yan-jun ${ }^{1, a}$, ZHANG Jian ${ }^{1, b^{*}}$, MAO Qing-yuan ${ }^{1, c}$ \\ ${ }^{1}$ Nanjing University of Aeronautics and Astronautics ${ }^{1}$, Nanjing 211106, P.R. China \\ alyj@nuaa.edu.cn, ${ }^{\mathrm{b}} 1540079310 @ q q . c o m,{ }^{\circ} 58011378 @ q q . c o m$
}

Keywords: Pipeline tapping machine, Design and manufacturing, Pressure balance, Body sealing, Remote control

\begin{abstract}
Pipeline transportation plays an important role in the resources deployment and economic development of our country. Its dimensional repair technique is an important guarantee to ensure the safety and reduce the loss. Tapping machine draws a lot of attention as the key equipment. According to project practice, key problems of the largest-diameter pipe tapping machine's design and manufacture in our country was discussed. Firstly, the development Status, opportunities and challenges was analyzed. Then, the requirements and theory of tapping machine design were analyzed; the design of features, accessories and control components was finished. The problems of tapping with pressure, pressure balance, body seal and remote control was solved. Finally, the problems in the manufacturing process of tapping machine like welding, deep hole and keyway in long axis were researched and the solutions were put forward. The successful use of the machine shows its usefulness and reliability.
\end{abstract}

\section{Introduction}

Pipeline transportation is one of the five major transportation methods, which is used to transport oil, gas and other resources. It is continuous, stable, rapid, reliable, large-capacity, small footprint, and low cost. It plays an important role in the economic development of our country. With the happen of corrosion, aging, destroy and other conditions, the pipeline needs to be maintained and transformed regularly to ensure the safety of production and less economic loss. When failure occurs, it needs to be repaired, installed equipment and replaced failure pipe sections with transformation nonstop [1].

Pipeline tapping machine is special mechanical equipment solving these problems. It is used to hole on nonstop transportation pipeline under pressure. A typical tapping machine is consisted of mainframe, tee joint, plywood valve, tool connector, drill, plug connectors, built-in handle plug shank and other auxiliary facilities [2].

With the development of economy and the increase of demand, the pipeline is developing towards large diameter, high pressure and long length. Accordingly, tapping machine is developing towards automatic, large size and under pressure. The improvements are reflected in power, transmission, control and monitor mode.

October 8, 2013, the pipeline from platform 13-1 from Yacheng to Hongkong appeared anomaly and the pressure kept decreasing. Leakage point was found at KP500 through investigation. After careful investigation of divers and ROV, some problems were found, such as two leaks on the southern side manifolds sled, the rollover of northern manifold sled protection cover, sea pipe suspended span. Pipeline Bureau is responsible for the maintenance task of the pipeline, considering our research team had made huge research on pipeline tapping machine, and kept long-term cooperation with Pipeline Bureau, they commissioned our research team to design pipeline tapping machine which can meet the demands. Based on the analysis of the relevant requirements, the research team developed the H1500 pipeline tapping machine. Based on the full research on the background of the development of the pipeline tapping machine and the combination of Mechanics, Hydraulics, Cybernetics, the paper explains how we design the main engine and give solutions to the difficulties appears in the progress of manufacturing. 


\section{Background of Pipeline Tapping Machine}

Company T.D.Williamson and FURMANITE are the mainly suppliers of pipeline tapping machine in the world. Their products cover almost all sizes of pipeline's tapping and plugging progresses, and the degree of modularization and serialization are very high. For the moment, only underwater tapping machine [3] produced by T. D. Williamson and TDW 936 [4], TDW 2400, IP1524 pipeline tapping machines produced by FURMANTINE manage to tap on nonstop transportation pipeline. Tapping ranges from $720 \mathrm{~mm}$ to $1524 \mathrm{~mm}$.

Domestic pipeline maintenance technology research in the last century in $80 \mathrm{~s}$, and manage to develop a partial size of pipeline tapping machine, ranges centralized from $500 \mathrm{~mm}$ to $1016 \mathrm{~mm}$, tapping diameter larger than 1000mm mostly are K1000 produced by Xinyu Flying Tiger Pipeline Technology Equipment Co, Ltd and KKJ1000 produced by GUNNERYS. CO, Ltd. In addition, Cai Bingde [5], Zhang Ruilin [6], Zhang Zhiji [7] has put forward new design of pipeline tapping machine.

The construction of large diameter pipeline in china started late, compared with the most advanced pipeline tapping machine, there still exists a giant gap among power mode, drive mode, control mode and monitor mode. The development of pipeline tapping machine is faced with great opportunities and challenges.

1) Opportunities: rapidly increased of energy consumption; rapid development of oil and gas pipeline construction; The monopoly of foreign companies makes it necessary to realize the nationalization; the increased proportion of technical personnel in the industry, which provides the conditions for the technical breakthrough.

2) Challenges: The domestic Pipeline tapping machine research starts late, and the technology and the experience are very weak; the high cost and the long cycle of the research.

\section{Design of Pipeline Tapping Machine}

Overall Design. According to our work, H1500 pipeline tapping machine needs to satisfy the following technical specifications:

Table 1. Technical specifications.

\begin{tabular}{|l|l|l|l|}
\hline Specifications & Parameter & Specifications & Parameter \\
\hline Diameter of tapping & $28 " \sim 60 "(711 \mathrm{~mm} \sim 1524 \mathrm{~mm})$ & Rate of spindle (cut) & $8 \mathrm{r} / \mathrm{min} \sim 15 \mathrm{r} / \mathrm{min}$ \\
\hline Travel of spindle & $160 "(4064 \mathrm{~mm})$ & Rate of screw (feed) & $0 \sim 20 \mathrm{r} / \mathrm{min}$ \\
\hline Design work pressure & $10 \mathrm{MPa}$ & Cutting feed rate & $0.07 \sim 0.08 \mathrm{~mm} / \mathrm{r}$ \\
\hline Hydraulic work pressure & $25 \mathrm{MP}$ & Rapidly feed rate & $8 \mathrm{~mm} / \mathrm{r}$ \\
\hline Work pressure & $1.2 \mathrm{MP}($ depth of water120m) & Material & X80 \\
\hline
\end{tabular}

According to the domestic demand and the research of existing pipeline tapping machine abroad, H1500 machine designs as shown in Fig. 1, the main points of structural design are as follows [8]:

1) Installation method: pipeline tapping machine main driving motor adapts underneath type and feed motor adapts overhead type.

2) Compensation: the compensation device is used to compensate the water pressure in the machine which is lower than outside environment.

3) The main driving motor dives driving sleeve while feed driving motor dives screw. There are threads out of the screw, and connect with spindle by nuts. Spindle connects with sleeve by the outer key and rotates and travels under the combined action of sleeve and screw.

4) The two-way seal device is installed on the bodies where contact with the sea water. On the one hand it can prevent sea water from flowing into the body; on the other hand it can prevent oil inside from leaking into the sea.

5) The shell body of the pipeline tapping machine is not formed at one time. Flange connection is adapted at the place where installed gear case, the seal position or the place with bearing. This design mainly makes it easy to assemble. 


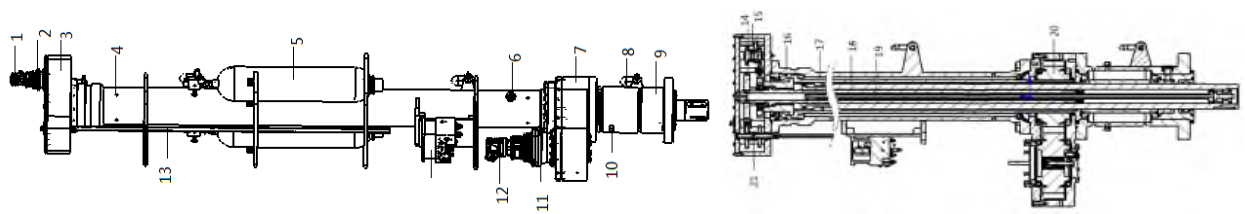

1. Feed motor 2. Transmission 3. Upper gearbox 4. Accumulator interface 5. Accumulator 6. Lock sleeve 7. Lower gearbox 8. Hanging ring 9. Spindle support box 10. Oil hole 11. Transmission 12. Driving motor 13. Ruler 14. Upper gear set 15. Gear device 16. Shell 17. Driving sleeve 18. Spindle 19. Screw 20. Lower gear set 21. Differential mechanism Fig. 1 Overall structure of H1500 tapping machine.

\section{Functional Design}

Main Structural Component. Pipeline tapping machine implement rapid feed and retreat through the feed motor driving screw to rotate and implement slow cutting through different rate between spindle and screw driving by drive motors. Its principle is shown in Fig. 2.
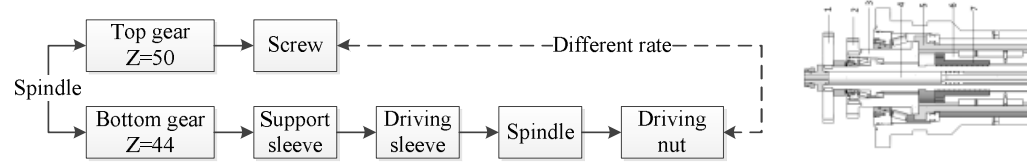

1. Top gear 2. Bottom gear 3. Support sleeve 4. Screw 5. Driving sleeve 6. Spindle 7. Driving nut Fig. 2 Schematics of tapping machine's differential.

Gear Design. Gear box is used to control feeding, technical specifications require rapid feed rate for $8 \mathrm{~mm} / \mathrm{r}$, while cutting feed rate is between $0.07 \sim 0.08 \mathrm{~mm} / \mathrm{r}$. We may choose $0.08 \mathrm{~mm} / \mathrm{r}$. Differential feed occurs between spindle and sleeve by upper gear box. According to differential calculation formula, the speed ratio of the spindle and screw speed can be obtained [9].

$$
\frac{\omega}{\omega^{\prime}}=\frac{8-0.08}{8}=\frac{99}{100}
$$

Based on the formula of gear driving: The recommended value are: $Z_{1}=25, Z_{2}=20, Z_{3}=50, Z_{4}=30$, $Z_{5}=Z_{9}=Z_{10}=18, Z_{6}=16, Z_{7}=Z_{11}=22, Z_{8}=44$. The arrangement of top gearbox is shown as Fig. 3 and we let modulus equal to 6 .

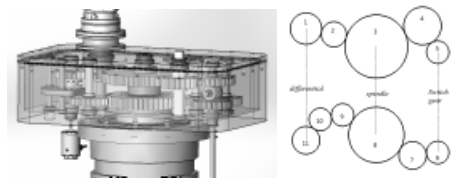

Fig. 3 Arrangement of top gearbox.

\section{Auxiliary Design}

Pressure Balance. The design requires $10 \mathrm{MPa}$ for pipeline pressure. Lower end face of spindle is dragged by the pipeline's inner pressure, so the accumulator is used to balance the pressure. The accumulator is designed as Fig. 4. It connects the end face of spindle with the pipeline inner pressure.

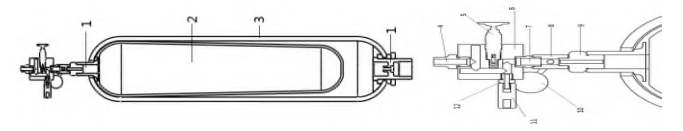

1. Accumulator's interface 2. Bladder 3. Case 4. Quick connector 5. Overflow valve 6. Cross connection 7. Barrel connector 8. Three-way junction 9. Joint 10. Pressure gage 11. Non-return valve 12. Transition joint

Fig. 4 Accumulator. 
Volume Compensation. In the design, working environment is required for underwater 120m; it will be affected by pressure from brine. Tapping machine has been oil-filled by itself. So balancing the water pressure is compensating the volume of engine body actually when the tapping machine works normally. Under the circumstance of the tapping machine is full of hydraulic oil inside the body, when the tapping machine works, with the spindle moves up and down, forming two cavities which are variable volume. One is the drive sleeve, namely, the cavity which is formed by the spindle in the bottom wall and screw down the face. The other is a cavity which is formed by the low inner wall surface of the spindle and the down face of the screw, as shown in Fig. 5. In the process of spindle motion, one of the cavity compresses, another expands. The hydraulic oil of the two cavities returns mainly by small holes or ring surface crack. It is easy to form hold pressure and increase the frictional pressure resistance. Thus, in the design of marine tapping machine's pressure balancing system, setting up two guide holes on the drive sleeve and upper position of the spindle which is used for connecting to the accumulator.
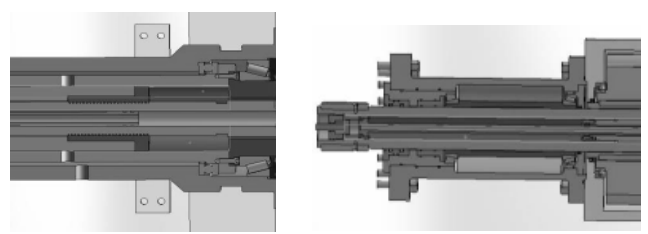

Fig. 5 Volume compensation.

\section{Control Design}

Shift Device. The function of declutch shift shaft: When the coupler of the tapping machine gear shaft are in a state of disengagement, at this time moving up through the shift shaft fork set, making the screw driven gear rotated. Through the intermediate inert wheel driving, screw driving gear drives screw rotated, so tapping machine spindle protruded downward in a straight line. Similarly, when the feeding motor rotates reversely, the spindle takes back in a straight line. Its structure is shown in Fig. 6:

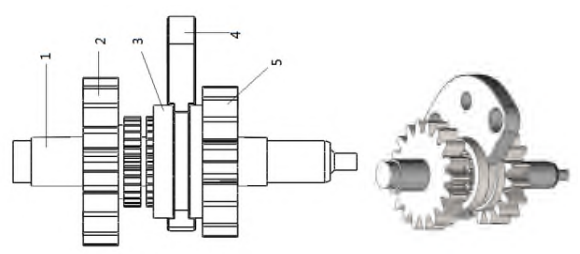

1. Shift shaft 2. Screw shift gear 3. Shift fork sleeve 4. Shift fork 5. Shift shaft gear Fig. 6 Shift system.

Hydraulic Principle. Hydraulic station is a clean and efficient opening drive system which is consisted of AV10 series of opening load-sensing pumps and other hydraulic products. With the tandem use of electrical proportional relief valve and electric proportional throttle valve, the oil pump flow and pressure proportion adjustment can be controlled [10]. With the signal of proportional valve is changed, the export oil flow and pressure of the pump changed. The motor output shaft's forward / reverse conversion is realized, so as to the transmission and control of H1500 hydraulic tapping machine is realized. Its schematic diagram is shown in Fig. 7.

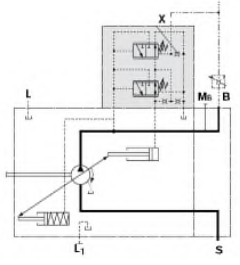

B. Working-oil way

S. Oil-absorption way

L1. Shell-oil discharge X. Forerunner pressure Mb. Measured working pressure

Fig. 7 Combined valve group. 


\section{Manufacture of Pipeline Tapping Machine}

Weld of Knife Blade and Body. Take various factors into consideration, the ASP 2048 and Q345C are respectively selected as material of knife blade and body. The microstructure, chemical composition and physical properties of two kinds of material are different, so the weld is dissimilar steel welding. The most commonly used welding method includes pressure-welding, brazing and melting-welding [11]. Pressure-welding needs high pressure on weldment. Melting-welding's temperature is exorbitant and will affect the properties of parent metal. By contrast, brazing cause smaller deformation to weldment and its heating temperature is moderate. So it is commonly used in the connection between different materials.

According to different pyrogen, brazing is divided into dip-welding, induction-brazing, resistance-brazing, flame-brazing and furnace-brazing [12]. The cutter tooth's structure is small in the projects, joint demand is high, so in the actual welding, the $90 \mathrm{kw}$ solid-state heating induction equipment is used to processing induction brazing, and it is concluded that a set of welding scheme called "three body cream", three body refers to the cutter tooth, $40 \%$ of the silver brazing alloy, cutter body, a cream refers to soldering paste. Through induction, it is heated to about $700^{\circ} \mathrm{C}$, melting silver brazing sheet, axially aligned after two seconds, the tooling which is close to the interior of the cutter body is used to ensuring radial accuracy. HRC is around about 60 after welding, and it is eligible via the inspection of X-ray.

Deep Hole Machining in Long Axis. In the designing scheme, the driven sleeve, the spindle and lead screw belongs to the typical structure of long axis deep hole, the difficulty of processing and workload are big, it is the common problem in large mechanical processing. According to the different processing mode can be divided into: General procedure such as drilling, boring, reaming; Precision machining method such as quilted grinding, rolling. Electric deep processing hole method such as EDM, electrolysis. The most use of long axis processing system at present includes BTA system, gun drilling systems, drilling systems and DF system [13].

The axis skew problem often occurs in the process of long axis deep hole machining easily, it is difficult to predict and control, but it will cause the machining accuracy can't meet the design requirements. There are many reasons which lead to axis skew. Literature [1] discussed some factors of affecting the hole axis, it includes processing method, cutting tool geometry parameter, guide sleeve eccentricity, the irregular flat of the workpiece which is to be drilled, the stiffness of drill pipe and the supporting location of the drill pipe. The methods which are the pre-drilling's prevention and the correction of drilling are proposed to reduce the deviation, there are as follows:

Before drilling: 1) Choosing the best way of cutting; 2) Choosing reasonable tool geometric parameters; 3) Improving the precision of guide sleeve; 4) Improving the quality of processed workpiece; 5) Improving the drill pipe stiffness; 6) Choosing the right means of vibration reduction.

In the drilling: 1) For larger through-holes which are processed by drilling - boring technology, adjusting the drilling technology to correct;2) Adjusting the cutter's geometry parameter to rectify a deviation;3) Adjusting the workpiece's axis location to rectify a deviation.

Deep Spline Machining on Long Axis. In the design scheme, the internal keyway of an entire body in the drive sleeve. Its processing has a larger difficulty, the research on this aspect is less in China, thus the project team proposed a pull method which is shown in figure 8 to process. Chip tool's height increased gradually, the processing of the keyway completed twice. This method has been successfully solved the processing of the long keyway which is in the long axis pores.

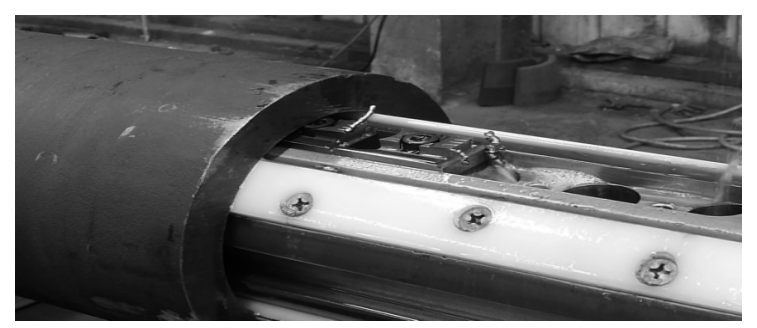

Fig. 8 Long key physical processing. 


\section{Summary}

The H1500 tapping machine was successfully used to maintain the gas pipe 13-1 in Yacheng from February to May this year without stopping transporting. There was not any fault in the process and the task was completed a month earlier than expected. The summary of this paper is as follows

1) Multi-disciplinary knowledge is used in this paper, such as machinery, hydraulic, control, overall-plan theory. Discussing the design and machining of the large-diameter ocean tapping machine which is high pressure and without transportation interruption;

2) Completing the design of the main function parts, gear box, pressure balance, volume compensation, sealing, shift device and hydraulic control of the tapping machine.

3) Discussing the hard problems during the machining of the tapping machine, such as the weld of blade and the knife body, long axis deep hole machining, the long axis of deep spline machining etc. The method which is used during actual machining is introduced in this paper.

4) In this paper, the tapping machine's bore diameter is the same as the international largest one, and the bore diameter is the largest in China. It can satisfy the large-scale pipeline's panning work of land and sea in China. It has been used in many emergency maintenance of pipeline successfully. It has an important impact on China pipeline maintenance.

\section{References}

[1] Y. G. Zhao. Research and development on the hot tap machine for large-diameter oil and gas pipelines. Nanjing: Nanjing University of Aeronautics and Astronautics, 2012.

[2] W. J. Zhou, R. Guo, Y. Zhang, et al. Application of holing and sealing technology on nonstop transportation pipeline with pressure. Pipeline Tech. Equip. 6 (2009) 35-38.

[3] B. James. Sullivan. Anderwater tapping machine: U.S.A, 4579484. Apr.1, 1986.

[4] D. A. Bill, D. D. William. High pressure tapping apparatus: U.S.A, 5439331. Aug.8, 1995.

[5] B. Cai, X. Y. Zhang. Pipeline hot tapping machine: China, ZL 200620118803.8. 2007-06-27.

[6] R. L. Zhang, L. G. Zhao, K. Q. Wu. The research and development of the new efficiency electric tapping machine used in pipeline with pressure. Mach. Des. Manuf. 12 (2010) 128-129.

[7] Z. J. Zhang, Q. Wang, W. K. Zhang, et al. Hydraulic tapping machine: China, ZL 200620092167.6. 2007-07-25.

[8] Z. S. Yu, H. Zhang, H. L. Zhao, et al. Design of underwater pipeline tapping machine. China Mech. Eng. 21(3) (2010) 268-270.

[9] A. X. Ma, Y. J. Li, et al. Design of the remote automatic control submarine pipeline tapping machine with pressure balance. Sci. Tech. Eng. 14(26) (2014) 66-71.

[10] Z. S. Yu, H. Zhang, H. L. Zhao, et al. The design of hydraulic control system in underwater tapping machine with pressure balance, Mach. Tool Hydraul. 35(9) (2014) 127-128.

[11] Y. Zhao. Brazing technology and application. Beijing: Chemical Industry Press, 2004.

[12] P. He, J. G. Jia, Z. X. Yu, et al. High-frequency induction brazing research and analysis, Electr. Eng. Tech. 32(1) (2003) 23-25.

[13] B. Zhang. Several deep processing technology. Mod. Manuf. Eng. 3 (2004) 120-121. 